Joint Transport Research Centre ROUND TABLE

20-21 October 2010, Queretaro, Mexico

N

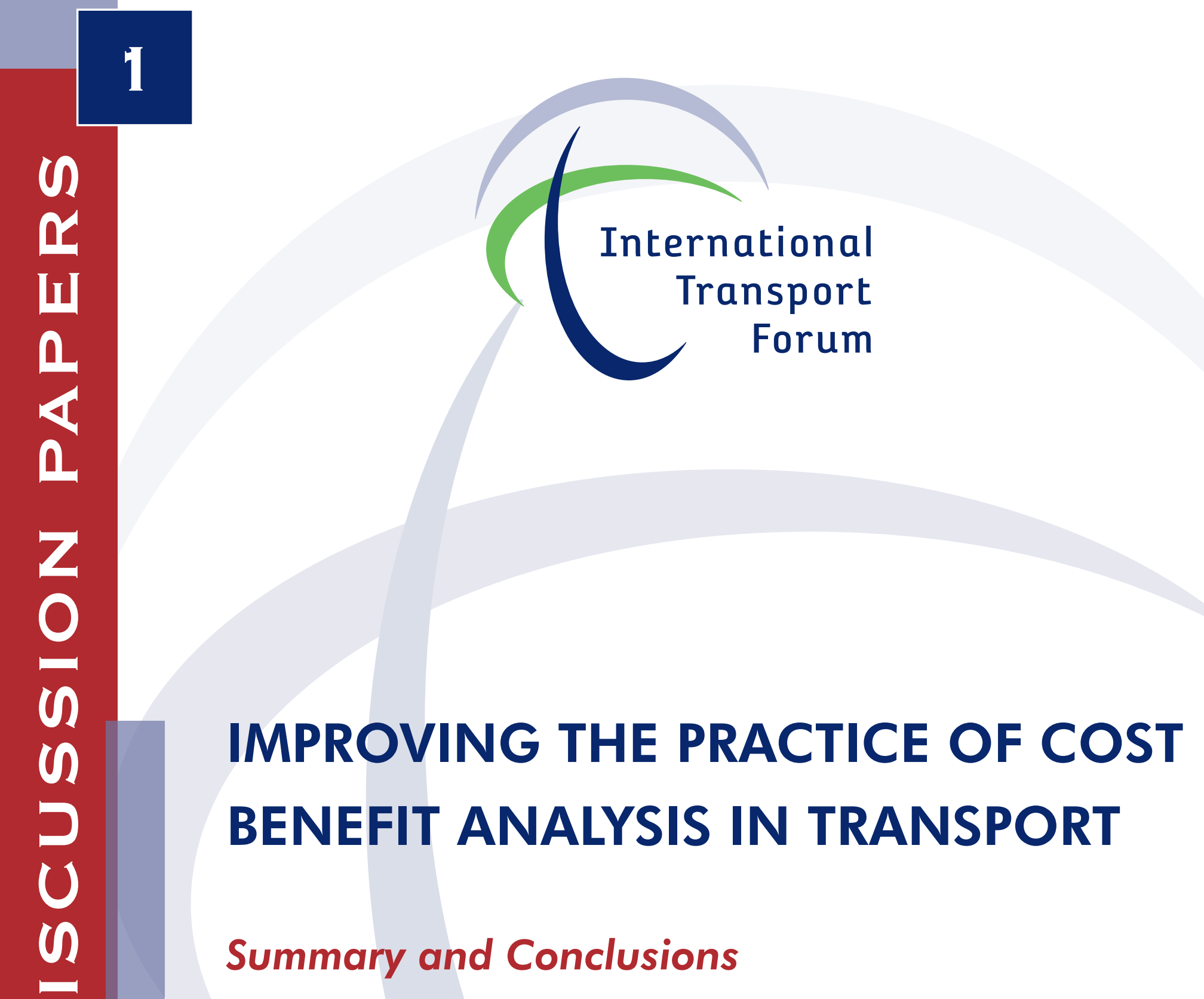


Discussion Paper No. 2011-1

ITF/OECD Round Table of 21-22 October 2010 on

Improving the Practice of Cost Benefit Analysis in Transport

Queretaro, Mexico

\section{SUMMARY AND CONCLUSIONS}

January 2011 


\section{International Transport Forum}

The International Transport Forum is an inter-governmental body within the OECD family. The Forum is a global platform for transport policy makers and stakeholders. Its objective is to serve political leaders and a larger public in developing a better understanding of the role of transport in economic growth and the role of transport policy in addressing the social and environmental dimensions of sustainable development. The Forum organises a Conference for Ministers and leading figures from civil society each May in Leipzig, Germany.

The members of the Forum are: Albania, Armenia, Australia, Austria, Azerbaijan, Belarus, Belgium, Bosnia-Herzegovina, Bulgaria, Canada, Croatia, the Czech Republic, Denmark, Estonia, Finland, France, FYROM, Georgia, Germany, Greece, Hungary, Iceland, India, Ireland, Italy, Japan, Korea, Latvia, Liechtenstein, Lithuania, Luxembourg, Malta, Mexico, Moldova, Montenegro, the Netherlands, New Zealand, Norway, Poland, Portugal, Romania, Russia, Serbia, Slovakia, Slovenia, Spain, Sweden, Switzerland, Turkey, Ukraine, the United Kingdom and the United States. The Forum's Secretariat is located in Paris.

\section{Joint Transport Research Centre}

The OECD and the International Transport Forum established a Joint Transport Research Centre (JTRC) in 2004. The Centre conducts co-operative research programmes addressing all modes of transport to support policymaking in Member countries and contribute to the Ministerial sessions of the International Transport Forum.

\section{JTRC Discussion Papers}

The JTRC Discussion Paper Series makes economic research, commissioned or carried out at the Joint Transport Research Centre, available to researchers and practitioners. The aim is to contribute to the understanding of the transport sector and to provide inputs to transport policy design. The Discussion Papers are not edited by the JTRC and they reflect the author's opinions alone.

The Discussion Papers can be downloaded from:

www.internationaltransportforum.org/jtrc/DiscussionPapers/jtrcpapers.html

The International Transport Forum's website is at: www.internationaltransportforum.org/

For further information on the Discussion Papers and other JTRC activities, please email: itf.contact@oecd.org 


\section{TABLE OF CONTENTS}

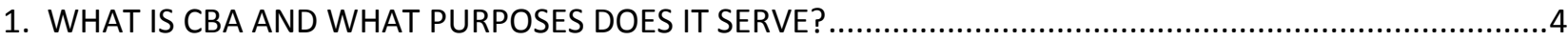

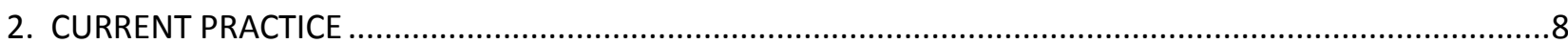

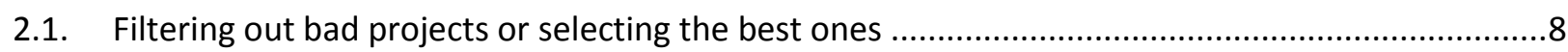

2.2. Other uses of CBA

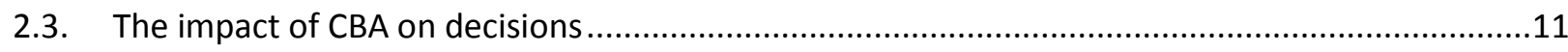

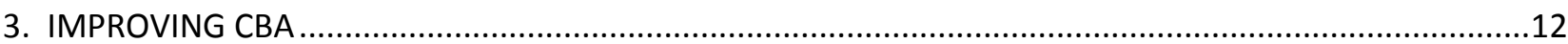

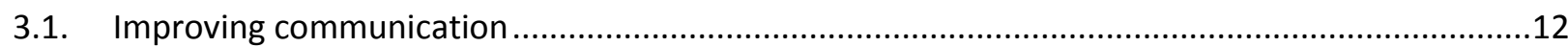

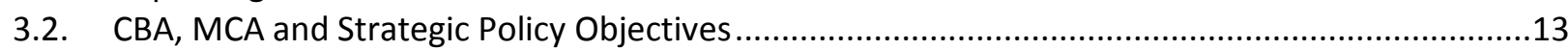

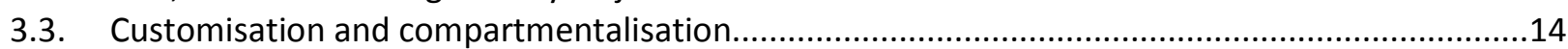

3.4. Discount rates, benefit-cost ratios, and costs of public funds .................................................15

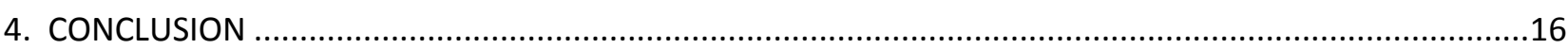

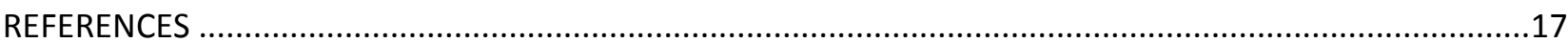

January 2011 


\section{Improving the Practice of Cost-Benefit Analysis in Transport}

Cost-benefit analysis (CBA) is widely recognized to be helpful, even indispensible, for making good decisions on what transport projects to fund. It essentially aims to figure out which projects offer the best value for money, one of the core criteria for making decisions. However, the practical relevance of cost-benefit analysis does not always live up to its appeal in principle. One problem is that there is disagreement about what to include in both the costs and the benefits side of the analysis, so that value for money is not always a fully transparent concept. A second problem is that value for money is only a partial criterion for decision-making, leading to disagreement about the relative importance of the results from CBA compared to other inputs into the decision-making process.

Discussions at the Roundtable aimed to shed light on these conceptual problems by analysing the practice of CBA and comparing approaches to it in different countries. In short the aim was to identify a checklist of items that should be included in a socially relevant cost-benefit analysis, i.e. analysis that can be produced in reasonable time and at reasonable cost but is good enough to help resolve trade-offs.

\section{WHAT IS CBA AND WHAT PURPOSES DOES IT SERVE?}

In order to make the best possible use of cost-benefit analysis in transport project appraisal a good understanding is needed of what CBA is and what it is not. This section provides a quick overview of how CBA works, how it is evolving and what are its shortcomings. Section 2 then goes on to consider the role of CBA in decision-making, taking account of the policy and institutional context, which varies across countries and over time within countries.

\section{CBA is a method for appraising the socio-economic impact of projects}

CBA is first a method for project appraisal, i.e. for assessing the impact that a project is likely to have on social welfare. Such evaluation implies comparison to other projects and/or to a do-nothing-scenario. Projects are broadly defined as discrete changes to the prevailing situation, often with multi-faceted impacts and objectives (Small, 1999, 137-138). CBA can be used for the appraisal of technical variants of a project, e.g. comparing different alignments for a planned bypass of a congested transport link. It can also be used for assessing clusters of projects, e.g. the construction of rail networks, for programming and hierarchizing a set of independent projects, either for the same mode or for different modes under a given budget allocation, and for strategic policy choices, e.g. in the context of decarbonisation or broader sustainability policy, or for deciding the relative shares of the public budget to allocate to transport versus other sectors. 
The level of detail and the emphasis of the modelling work need to be adapted to the particular context of the appraisal. For example, when comparing two bypasses, the focus will be on calculating time savings through a transport network model and on construction costs and environmental and safety impacts. But where decarbonisation is concerned, broad trade-offs between environmental concerns, public finance, and the pros and cons of various types of spatial development patterns need to be addressed. The methodological principles underlying the analysis (those of welfare economics) are the same in all cases, but when appraisal moves into the planning and policy arena, narrow time, cost and safety concerns will no longer suffice to obtain a good appraisal; instead, more attention will need to go to the impacts on spatial distribution of activities, on macro-economic impacts and on the definition of the transport problem itself (Tomlinson, 2004). At the heart of current debates about CBA are its suitability as a framework for handling these meso-economic questions.

In principle CBA is equally applicable to private and public projects, but because of its focus on social welfare (instead of, e.g., profits) the method is most frequently used for public decision-making. CBA could be used in the appraisal of all kinds of public projects, e.g. building a new school, or hospital, but in practice it is more often used in the transport sector than in other sectors. CBA can be applied to infrastructure projects and also to other policy measures, e.g. comparing the impacts of alternative ways of pricing the use of transport networks.

That CBA is used more often in transport than in other sectors is a potential cause for concern. If non-transport projects work with a different metric, allocating funds across sectors in a way that is explicitly aligned with expected social benefits, as calculated in CBA, is not possible. And if CBA is conservative in estimating benefits, as is sometimes believed (see below), then it is possible that its use in transport weakens the political case for steering funds to the sector. On the other hand, the prominence of CBA for evaluating transport sector projects (at least in the countries that use it systematically) means that the sector has a clear idea of how much value for money it generates, and this can strengthen its case in arguing for budgets. It is plausible that this helped limit the impact on the transport sector of the significant overall public spending cuts that took place in the UK in the Fall of 2010.

The apparatus of CBA is designed to estimate costs and benefits as well as possible in order to make statements on net benefits ("value for money") with a reasonable degree of confidence. The core methodological approach of $\mathrm{CBA}$ for transport infrastructure is to measure benefits through the willingness of users to pay for the transport benefits, i.e. the "direct benefits" of the infrastructure. The choice to work with willingness-to-pay reflects the welfare economic fundamentals of the method: what matters in the end are consumer benefits. The approach to work with direct benefits to users can be seen as one rooted in practicality. A transport infrastructure project will affect travel times and more generally the benefits of travel that accrue directly to users. Traffic models help analysts form a picture of what these direct effects will look like. Measuring user benefits is far easier ${ }^{1}$ than tracing the ultimate incidence of project impacts throughout the economy, and therefore provides a practical avenue to producing robust results relatively quickly. Practicality, however, comes at a cost in terms of scope and policy-relevance. The scope issue arises because direct user benefits represent total benefits only under restricted conditions. Relevance becomes a problem when policy-makers are less interested in total benefits than in distributional impacts whether by income group or spatially. We discuss these issues in more detail under the next two headings.

1 Although it is not easy in an absolute sense for reasons of data, model, forecasting and valuation error. 


\section{Extending the scope of CBA}

With respect to scope and accuracy, user benefits are an exact measure of total benefits only if there are no external costs or other market imperfections and if returns to scale are (locally) constant. Since neither condition holds in reality, user benefits, even if correctly measured, are only an approximation to total benefits. This shortcoming of standard CBA has long been understood, and much progress has been made with conceptualising and quantifying the impacts ignored in standard CBA. The inclusion of some external costs (e.g. local pollution, congestion) is known to be important for good appraisal in a very wide range of situations. For other, broader impacts, there are strong indications that they are worth exploring in at least some circumstances, notably the agglomeration impacts of large urban projects.

The most commonly used method is not to replace the direct benefits approach of CBA with an alternative and more comprehensive concept of impacts (e.g. through general equilibrium modelling), but rather to extend the direct benefits approach with "add-ons" to capture a broader range of impacts. As argued in more detail below, this gradual approach makes methodological sense given the limited operational viability of alternative methods, but it may pose problems in the understanding of CBA that contribute to scepticism regarding the method's validity.

Whatever the shortcomings, the add-on approach has broadened the scope of CBA considerably. For example, the inclusion of the impact a project has on a range of external costs (environmental and health impacts, safety, congestion, etc.) is more or less routine in practice, and standardised approaches to modelling and measuring them are emerging. Standardised procedures for project appraisal are emerging at an international level with, for example, the HEATCO report (Bickel et al., 2006) and RailPag (EC-EIB) work in Europe.

A more recent and more controversial development concerns the inclusion of "wider economic impacts" in appraisal. The wider impacts include effects on productivity, agglomeration, competition and labour markets (see Vickerman, 2007, for a discussion). While some of these effects are not very clearly defined and there may be overlap between them, it is widely accepted that the effects are real and sometimes potentially important. There is less agreement, however, on what this means for the practice of appraisal.

The influential Eddington study (Eddington, 2006) argues there is sufficient empirical evidence that agglomeration economies are important for some, typically large, projects and that they should be included in appraisal of these types of project. The Crossrail ${ }^{2}$ project in London is a classic example of a case where agglomeration effects should be included - a very large project that will significantly alter access to places of work for thousands of people. Not including these benefits where they are likely to exist tends to understate the benefits of transport projects and creates a risk of underinvestment. It also biases the allocation of funds between transport projects with high and low agglomeration benefits.

Some recent studies (Graham and Van Dender, 2010; Gibbons and Overman, 2009) take a close look at the empirical evidence on agglomeration economies, and conclude that it may not be precise and solid enough for inclusion in routine transport project appraisal. These authors argue that the conceptual case for the existence of agglomeration economies is strong and supported by ample evidence but that it is not yet possible to transfer this evidence to the context of a typical transport infrastructure project

2 http://www.crossrail.co.uk/. 
(which is much smaller than, e.g., Crossrail). This work brings further support to the conclusion of a 2007 ITF roundtable on wider economic impacts of investments in transport infrastructure (ITF, 2007), that using rules of thumb to account for agglomeration benefits in CBA is not best practice. Investigating the existence and size of agglomeration benefits makes sense for large and very costly projects but the evidence suggests it would be misguided to treat agglomeration as a general boost to the benefits of transport infrastructure investment, representable by some kind of average mark-up.

\section{$C B A$, total costs and benefits and their distribution}

Even if CBA produces a good approximation to total costs and benefits, this knowledge provides little information on how cost and benefits are ultimately distributed in the economy (project incidence). This is a problem because incidence is relevant to decision-making. The evolution described under the previous heading, by which CBA gradually expands its scope and comprehensiveness through add-ons to the core method, does little or nothing to improve the representation of incidence and distributional effects.

In order to determine the full distributional impact of transport projects, it is not enough to establish the direct impact of the project on different user groups, because direct impacts can differ strongly from the ultimate impact after all channels of transfers (and wider impacts) have played out. Tracing the ultimate incidence of project impacts requires a model of the economy that distinguishes at least the main groups that could be affected by that project, for example a spatial general equilibrium model that distinguishes between various types of households and the effects on various locations. Welfare economists have spent considerable effort on establishing methods for considering efficiency and equity impacts simultaneously. In principle, when thought necessary the job can be done. ${ }^{3}$ Nevertheless, operational models are not yet routinely available and such assessments remain costly and timeconsuming. The consequence is that attempts to describe the likely ultimate incidence of the impacts of transport projects are relatively rare and cannot up to now aspire to a high degree of accuracy.

To summarize, a basic CBA provides a framework for addressing a fairly limited question ${ }^{4}$ : what are the likely net benefits from a transport project? This information is useful for supporting decisions on what projects and project options to fund, but it is not sufficient, as it provides no, or very imprecise, information on a range of effects that policy-makers care about. The scope of the appraisal can be broadened and precision can be increased, but this will increase costs and the time taken to produce appraisals, and informational and methodological constraints do impose real limitations on how far the appraisal can be taken. What is possible varies between countries -- some countries have a strong tradition in regional economic data and modelling, others do not. Even if all potentially relevant effects were described as well as possible, it should not be expected that project funding decisions will be made

3 Views differ on whether it is necessary to consider the distributional impact of every project. If there is a multitude of projects and other changes to the economy, then focussing on the distributional impacts of a single project is not necessarily useful at the country level, though local public authorities or socio-economic groups can be highly interested in them.

$4 \quad$ Limited but important. One view is that net benefits are all that matter, as accompanying measures can be used to achieve distributional objectives (see Kaplow, 2007, who revises the position from welfare economics that equity and efficiency should not be separated in appraisal, and is careful to point out this holds only under particular separability assumptions for household preferences). Project appraisal then still could usefully include a description of distributional effects, but these effects should not play a role in the decision whether to go ahead with the project or not. 
on the basis of appraisal alone. Appraisal informs decisions, but is not a decision rule, as is clear from the gap between the insights from CBA and real decisions. Against this background, the next section discusses the role of $\mathrm{CBA}$ in decision-making.

\section{CURRENT PRACTICE}

\subsection{Filtering out bad projects or selecting the best ones}

We argued in the previous section that in principle CBA is applicable to any project. In the context of transport, CBA can provide insight into the effects of small improvements as well as major changes to a network, and into programming as well as strategic policy choices. Within this broad remit, the way the methodology is implemented needs to be adapted to the context. These remarks abstract from the broad context in which project appraisal takes place, assuming implicitly that this context is receptive to CBA. In practice, however, CBA - if used - has a different function depending on where and when it is used. The weight given to CBA in decision making can be large, small or even zero, depending on the broad culture of decision-making that applies. Similarly, the potential contribution of CBA to the quality of decision-making depends on the broad policy-making context.

A complete discussion of what determines, or should determine, the exact role of CBA in decisionmaking is outside the scope of this paper. Nevertheless, a comparison of practice in France, Mexico, and the UK suggests that the function of CBA partially depends on the characteristics of the portfolio of projects that are subject to CBA. ${ }^{5}$ Figure 1 is a stylised representation of this dependence. If the portfolio of potential projects is expected ${ }^{6}$ to be of high quality (in the sense of being well documented, with strong preliminary assessment by the promoters), CBA can help refine final project selection so as to make the best possible use of available funds. With an expectation of a low quality portfolio, the emphasis probably should be on weeding out the worst projects. If CBA acquires a reputation that bad projects are likely to be identified and selected out, then over time it will help raise the average quality of projects submitted. This behavioural role of the appraisal regime is very important.

5 Casting the discussion in terms of a portfolio suggest there is a large number of smaller projects under consideration. The principles involved, however, are not limited to small projects: distinguishing basic quality control from quality optimisation is useful for small and large projects as well as for strategic policy principles.

6 We prefer to express the relation in terms of expected quality, as there is no certainty about the quality of individual projects and the expectation can be seen as reflective of the overall decision-making culture. 
Figure 1. The focus of CBA depends on the (expected) quality of the project portfolio

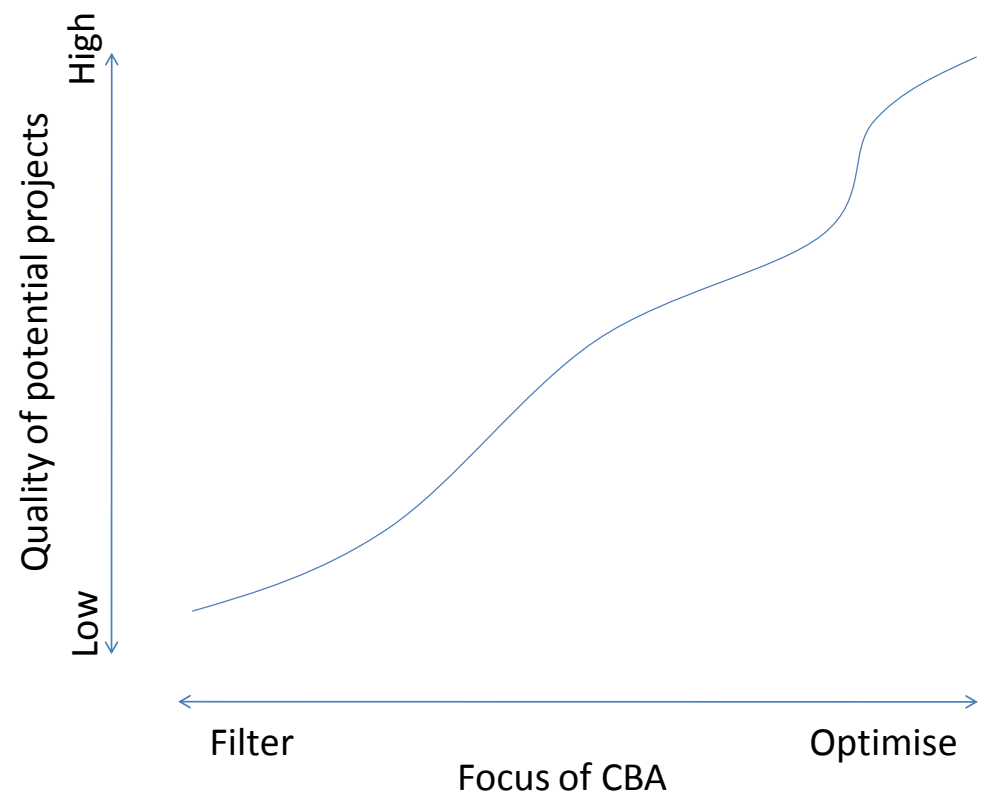

Many factors determine the quality of the initial portfolio, including the capacity of promoters to carry out project design and the general state of the transport network (with either high or declining marginal returns to investment). To be clear, the notion of quality does not refer here to the likely social rate of return of a project, but to the overall "case" for the investment. In fact, in situations where there are many high-yield projects, the quality of the average project case could be low, as there is an expectation that most projects are beneficial. CBA then can usefully focus on selecting out poor projects that try to game this expectation of high average benefits.

The role of CBA in Mexico is very much to filter out bad projects (Ramirez Sobranis, 2010). It appears that the main purpose of appraisal is to impose discipline on the project selection process through appraisal requirements that are both rigid and narrow. The requirements are rigid in the sense that they are described in detail and no funding can be obtained without passing the CBA test (obtaining the minimal rate of return of $12 \%$ ). The need for discipline in an environment with a virtually limitless supply of relatively high-yielding transport spending options is easily appreciated. Rigid appraisal requirements almost certainly outperform the alternative where project selection is essentially random, even if rigidity means a good project is occasionally filtered out.

However, the Mexican appraisal process is also narrow, in the sense that only a limited range of direct impacts is taken into account. The rationale offered for a narrow interpretation of cost and benefits is that broader impacts are increasingly less tangible and their quantification therefore harder and more susceptible to manipulation. This argument is flawed for at least two reasons.

First, omitting certain project impacts from the appraisal implies the risk of introducing systematic bias in project selection. Excluding safety impacts, for example, may induce unduly cheap solutions to capacity expansion that minimise cost by omitting critical safety features. Ignoring environmental impacts can lead to a bias across modes, e.g. favouring transport by car over public transport modes. 
Broadening the scope of the CBA reduces these problems. While in principle CBA could produce an unbiased comparison of alternative projects, in practice there are difficulties with comparisons between different transport modes and between different types of projects (e.g. those providing access and those expanding capacity). Projects with very different life spans and cost recovery periods can also be difficult to compare. Given these practical limitations to CBA, other criteria or indicators need to be used. Such indicators can be based on strategic policy priorities. Strategic policy choices can also be used to allocate resources to different types of projects (e.g. to metalling rural roads) prior to CBA, using the latter to rank projects within like groups of projects.

Second, not quantifying an impact because it is difficult to quantify implies a judgment that no number is better than an imprecise number. This is sensible in situations where no confidence interval can be associated with an estimate, as in that case the estimate provides no information. In many situations, however, the accuracy of the estimate of an impact can be quantified. Then it is better to use the imprecise number and be explicit about exactly how small or large the confidence interval is. Even with low confidence levels, using ranges of values is useful because they are made explicit. In general, explicitly recognising uncertainty is better than limiting the analysis to areas where uncertainty is low. The final process of project selection then can turn to the appraisal to inform judgments about various uncertain impacts, instead of relying on less formalised criteria to base choices upon (as seems to be the case in the current Mexican process).

Figure 1 suggests that, where the portfolio of projects is of good quality, appraisal should shift its focus toward identifying and hierarchizing the best projects and choosing the best technical variants. Where networks are mature, additional investments can be expected to have a lower return on average, justifying closer scrutiny. The main risk now is that projects with low returns do go ahead and displace alternative (better) ways of spending the money; the main risk is no longer that a project that is much better than alternatives is stopped (which is the main potential error introduced by a rigid and narrow approach). The type of appraisal used in France and in the UK, which accounts for a broader range of impacts and takes a longer run view than in Mexico can be seen as exemplifying this shift in emphasis. Two caveats should be mentioned here though:

Our use of France, Mexico, and the UK as examples reflects the available background material and implies no judgment that network maturity or generally higher economic development levels automatically imply a need for appraisal to focus on the optimisation of resource use. Not all economies with incomes and networks comparable to France and UK rely equally strongly on CBA as France, Mexico, or the UK do. And in some countries the culture of decision-making is such that focussing on CBA as a filter seems more justified, even if networks are well-developed and incomes high.

Figure 1 is normative in the sense that it proposes a role for CBA in project selection where the average submitted project is of high quality. In practice, however, there is a recent tendency to rely less on CBA for funding decisions in countries like France and the UK (see Mackie, 2010, and Quinet, 2010). Some possible reasons for this evolution are discussed in the next section. In general they reflect a judgment that CBA on its own does not perform as well as hoped for in carrying out the proposed role. 


\subsection{Other uses of CBA}

The method underlying CBA is applicable to small or large projects, as well as to programs or to master plans and strategic orientations. Choices on what to emphasize and how much detail to include depends on the object to assess, but in principle the tool is sufficiently versatile. Nevertheless, applying CBA poses some problems where large projects, master plans and strategic orientations are concerned. CBA in its present apparatus is very well-suited for the evaluation of small projects, i.e. projects that have only little impact on overall price levels throughout the economy. In order to be well adapted to the assessment of investment programs or, more broadly still, the choice of a strategic policy direction that implies "transformational" choices, the methods need to be extended, moving from a highly partial to a more general framework that allows for changes in relative prices and that extends the time horizon. In such a framework, CBA is able to enlighten decisions on project prioritization or the timing of implementation. CBA is extremely useful for comparing different ways of solving a well-described and limited problem but provides less precise guidance in terms of strategic policy choices. Although this is a seemingly straightforward observation, CBA is nevertheless used for providing strategic policy guidance and then found wanting. Despite the rather poor understanding of what economic interactions matter and how precisely they can be measured, applying CBA to more comprehensive projects provides very useful insights to the decision makers, as has been recently demonstrated by the overall assessment of the current French master plan.

Tensions between the broad policy planning level and the appraisal level can and do arise. What happens, for example, to projects that pass a CBA test but that lead to increased carbon emissions (e.g. extra capacity at severely congested hub airports), when the strategic policy choice is to decarbonise the transport sector? Or to projects that do not pass a CBA test but are thought to contribute to decarbonisation (e.g. some high-speed rail projects)? It seems unreasonable to halt every project that increases CO2-emissions (in a significant way) even when the broad goal is to reduce the transport sector's emissions, just as it seems unreasonable to accept all projects that reduce carbon-emissions irrespective of cost. CBA can be extremely useful in quantifying this tension between an individual project's merits and the broad thrust of policy.

\subsection{The impact of CBA on decisions}

In practice, the impact of $\mathrm{CBA}$ on the ultimate decision varies over time and place. At present, both in the UK and in France, CBA weighs less on decisions than it used to while discretionary strategic policy considerations have moved to the fore (see Mackie, 2010, and Quinet, 2010). The strategic policy considerations relate to sustainability (with a heavy focus on carbon emissions) and to economic growth (so that productivity effects take priority over user benefits). The strongly expressed view of roundtable participants was that increased attention to broad strategic policy objectives should not reduce the importance of CBA in assessing an individual project's merits in comparison to other projects or in relation to strategic goals. 


\section{IMPROVING CBA}

The previous sections provided an outline of what $\mathrm{CBA}$ aims to achieve and how the role of $\mathrm{CBA}$ depends on the decision-making environment in which it is embedded. A general observation is that CBA remains controversial everywhere. Sometimes this is related to misunderstandings of what it does, or to disagreements about the value set, and sometimes there are concerns about its misalignment with the broader policy framework. CBA introduces rigour into decision-making processes, and while it should not tie decision-makers hands it does increase transparency, accountability and rationality, and counters subjectivity in decision-making. This is its principal objective. How can that objective be pursued more effectively than at present? This section provides some suggestions.

\subsection{Improving communication}

CBA focuses on direct user benefits because they are a good approximation to total benefits and easier to measure than ultimate benefits, not because of any decision to narrow down the analysis. This point is often not understood and is a perennial issue in communicating the results of appraisal. The direct impact of a project, e.g. time savings, will translate into improved accessibility for various activities (work, school, leisure, shops, etc.) and into increased economic activity. Importantly, these are translations of benefits, not additions, so counting them twice would mean double-counting. Whereas current debates focus on expanding the scope of CBA, the earlier concern was to avoid such doublecounting. For example, Mohring (1961) states:

"Among the benefits of highway investment to which reference is commonly made are those presumed to accrue to property owners. [...] such gains are quite properly labelled "non-user benefits." [...] they are regarded as benefits that must in some way be added to those arising directly from highway use [...]. Although widely accepted (particularly among highway planners), this final conclusion is, as it happens, fallacious. That property values increase in the vicinity of highway improvements does reflect the existence of highway benefits. Increases in land value are not in themselves net highway benefits, however. Rather they reflect an actual or potential transfer of benefits derived from highways from one population group to another."

Though measuring direct user benefits does not account for the distribution of benefits and their transformation it does succeed in capturing total overall benefits. In principle the problem could be overcome by detailing the final incidence of impacts. Not only would this alleviate concerns about narrowness, it would also provide much desired policy insight into distributional effects. However, implementing such an approach in practice is not possible on a routine basis unless one is willing to accept a major reduction in the degree of confidence underlying the analysis and/or sizeable increases in time and financial resources. 
Stating that communication of the results of CBA needs to be improved is easy and commonplace but providing concrete recommendations on how to do it is not. One suggestion is to spend a bit less energy on pushing the technical boundary of CBA and more on presentation and discussion of results. A clear and succinct presentation of the different components of costs and benefits included in the analysis is key, and probably does more for the credibility of the analysis than fine-tuning the value of some poorly understood parameter. Second, CBA should limit itself to what it can do, and not try to meet requests to include ever more effects of which knowledge is lacking. This does not mean that CBA should ignore concerns about relatively vaguely defined concepts such as sustainability or liveability. Instead, analysts should ask planners to be explicit about what intermediate goals (e.g. urban form) promote sustainability or liveability. They might then use appraisal to help establish what policies work in the desired direction. CBA could become more agile in responding to changing priorities in policy-making without giving up the rigour and internal coherence that characterises it.

\section{2. $\quad \mathrm{CBA}, \mathrm{MCA}$ and Strategic Policy Objectives}

Multi-criteria analysis (MCA) is often proposed as an alternative to CBA that is superior because it addresses a broader range of project impacts, speaks more directly to decision-makers' concerns and is open to alternative assessments of the weights that various impacts receive. The opposition of MCA and CBA, however, seems largely artificial and the discussion that follows suggests that in fact there is considerable overlap and synergy between the methods.

MCA usually includes CBA for a project's impacts on economic efficiency and then monetises less tangible impacts to derive an overall quantitative (usually monetary) indicator of the broader net value of the project. MCA remains restrictive in that for some impacts, satisfactorily objective monetisation techniques have so far proved elusive (e.g. for landscape impacts).

One feature of MCA is that it enables different weights to be attached to different aspects of the evaluation. In CBA, the weights (that is, the monetary valuation of physical effects) are determined on the basis of the best available evidence. In MCA, weights can reflect evidence, expert opinion, or maybe even policy preferences. The MCA approach is useful when evidence is poor or absent. However, defining weights on the basis of policy preferences introduces subjectivity into the analysis and in the extreme defies its purpose.

This means that the strength of MCA is also its great potential weakness. Decisions on the weighting criteria employed can be critical in determining outcomes but they tend to be hidden in the detail of the analysis. Although scenarios can be produced on the basis of different weightings to illustrate their impact, it is difficult to present this to decision-makers in a way that is sufficiently concise and transparent.

The response in some countries has been to employ a MCA approach without deriving a single quantitative indicator of net value, in order to avoid pre-empting decision. An example is the UK's use of appraisal summary tables under the New Approach to Appraisal (NATA) introduced in 1998 for road projects. This has since been developed to cover investments in all modes and for multimodal studies and incorporates strategic environmental assessment for large projects. "Guidance on Multi-Modal Studies" was issued in 2000 and introduced the Appraisal Summary Table. This takes the form of a single page designed to highlight information relevant to current economic and other policy objectives. It includes statements of net present value of the project to users and to government and monetary indicators of 
value in improving safety and accessibility. Environmental impacts are listed in a variety of ways. Noise impacts are recorded by the number of properties affected. Climate change impacts are indicated by tons of $\mathrm{CO} 2$ added or avoided. Other effects are given a simple score depending on whether they are expected to be minor, significant or a major element for consideration. The list of factors covered can be added to according to current government policy priorities and includes impacts on landscapes, heritage sites, biodiversity, physical fitness, reliability, wider economic impacts, severance, transport interchange facility and land use policy. No weighting is applied to the different indicators. The decision maker is left to make the trade-offs involved in choosing whether to advance the project.

The focus of more traditional MCA is largely a discussion about what weights to attach to various impacts. The methods of measuring the impacts themselves do not necessarily differ from those used in CBA. Recent evolution in France (see Quinet, 2010), where decision-makers increasingly favour MCA techniques but appraisal practice still largely follows the techniques developed for CBA, suggests that both approaches can co-exist. The perceived tension between MCA and CBA may partly be a reflection of the (real) tension between CBA and strategic policy analysis, as MCA allows more flexibility in selecting weights to match policy priorities.

Ultimately CBA needs to contribute effectively to the decision making process. How this is best achieved is a matter of tradition, culture, politics and geography. It may be achieved by developing tools such as the UK appraisal summary table. It can also be achieved through institutional financing arrangements. Funds can be distributed to government bodies responsible for different types of project according to overall priorities. For example funds for development of tertiary roads in remote rural areas might be allocated to regional or local governments to spend on these kinds of projects rather than trying to arbitrate between these investments and projects of a very different nature, for example urban tolled motorways.

\subsection{Customisation and compartmentalisation}

In an idealised situation where all relevant aspects of a project are included in a $\mathrm{CBA}^{7}$ and can be evaluated with a reasonable degree of confidence, CBA could be the sole criterion to decide upon the allocation of a given budget across projects. The appraisal method would be identical across all projects and benefit-cost ratios would be used to rank them. In practice, CBA does not live up to that potential, and the pragmatic approach is to customize the appraisal method to different types of projects and to rely on other criteria in addition to benefit-cost ratios to allocate funding.

As an example of introducing other criteria for decision-making, the EIB de facto accepts lower rates of return for urban transport projects than for road projects. This contributes to aligning the share of funding that goes to public transport projects with the priorities of the bank's shareholders. While such differential treatment could be criticized in a world of perfect CBA, the practical shortcomings of CBA make such additional criteria useful. In these circumstances the key requirement is that there is transparency and accountability regarding these additional criteria.

Adapting the appraisal method to the type of project at hand goes one step further than allowing different threshold rates of return (for possibly identical appraisal methods). Discussions revealed broad 
consensus that such customisation is justified. In practice, CBA is very well suited to comparing projects that concern the same mode, e.g. different road projects. Intermodal comparisons are more problematic. Furthermore, CBA is strong in evaluating road projects, but weaker for other projects. The reason is that key inputs to the analysis, including such basic issues as capacity measurement, are harder to define in non-road modes. It follows that CBA does not provide complete guidance for intermodal comparisons, even if the projects are similar apart from mode.

The scope and the role of CBA hence changes when the decision-set broadens. This becomes even clearer when project contexts are hard to compare. The key impacts to be expected from building a rural road differ strongly from those of projects that expand capacity in an urbanised setting, and the appraisal method should reflect those differences. This highlights the need for additional criteria rather than an inadequacy of the appraisal technique itself and as already noted appropriate indicators can be derived from strategic policy when this is clearly stated.

\subsection{Discount rates, benefit-cost ratios, and costs of public funds}

The Mexican CBA practice, in line with the approach used by the World Bank, imposes a minimal internal rate of return ( $12 \%$ IRR at present) that projects must attain to be eligible for funding. Internal rate of return (IRR) is calculated as the interest or discount rate at which the net present value of costs and benefits of an investment are equal. Because of the discounting involved in the calculation, requiring a high internal rate of return (such as $12 \%$ ) disadvantages projects for which the benefits accrue further in the future. It may also give an inappropriate incentive to project promoters as one can expect all projects to take the hurdle, but not necessarily by a large margin. The practice in European countries including the UK and France is to use much lower discount rates (3-6\%). The selection of what projects to fund then relies on comparisons of benefit-cost ratios, rather than internal rates of return (which because of the way they are calculated compound the size of benefits relative to costs with the time period in which they occur). The "European" approach avoids a confusion of project selection criteria and appropriate discounting practices. It also allows differences in views on how to compare present and future financial flows to be reflected in differing discount rates. ${ }^{8}$ One could argue that requiring a high internal rate of return is more straightforward in a context where there are many immediate problems to solve, but the same results can be obtained by relying on benefit-cost ratios with the additional benefit of improving the comparison of projects with strongly different payoff paths. The discussion in earlier sections suggests there is a move away from rigid criteria, reducing the practical value of thresholds in decision-making.

France lowered its discount rate for transport project appraisal from 8\% to $4 \%$ in 2006 (and to 3\% for flows occurring 30 years or more into the future). Shortly thereafter it also started valuing the marginal cost of public funds at 1.3 instead of 1 . This means that each Euro used to build infrastructure receives a weight of 1.3 in the CBA, and this is justified because of the efficiency cost of raising the tax revenue needed to fund the infrastructure. ${ }^{9}$ These changes can be seen as improving the conceptual rigour of French appraisal. Whereas before the discount rate for appraisal (8\%) seemed high in comparison with social discount rates, it is now more in line with common EU values. Using a lower discount rate conceivably increases the number of eligible projects, but this is counteracted by introducing a higher

8 See Layard and Glaister, 2001, Introductory chapter, for a more detailed discussion.

9 The marginal cost of public funds refers to the costs of market distortions caused by taxation and is not related to concepts that concern the financial cost of borrowing. 
marginal cost of public funds. The conceptual case for the innovation is solid: the evidence that marginal tax increases carry high marginal efficiency costs in countries where taxes are already high is strong, and using a specific parameter is better than indirectly accounting for the cost of funds through high discount rates $^{10}$.

The use of a marginal cost of public funds (MCPF) bigger than 1 reflects a view that using public money raised through distortionary taxation has an efficiency cost that needs to be accounted for in appraisal. Values ranging from 1.2 - 1.5 are typical and are obtained mainly by calculating the marginal efficiency cost of raising revenue through tax on labour, the main and probably the most distortionary source of tax revenue in advanced economies. It is worth noting that the relevant MCPF depends on what source of tax revenue is considered. Non-labour tax revenue can come at a lower or higher cost than labour tax revenue. Tax revenues raised in the transport sector itself, possibly through the project under analysis, may well display a lower efficiency cost, given that a sizeable share of transport flows relates to leisure and not to work activities. Putting source-specific values on tax revenue flows then becomes part of the appraisal, implying that in principle project design and funding structures should be analysed together, not separately. More broadly, the marginal cost of public funds is just one factor in the comparison of various sources of public and private funding and it does not imply that private funds are universally preferable where they are available.

\section{CONCLUSION}

CBA is and remains a valuable tool for bringing structure, rationality and transparency to infrastructure decisions and strategic policy choices. The tool is not in itself sufficient to make decisions, and current decision-making processes show that decisions do not always follow the recommendations of CBA. Nevertheless, more consistent use of CBA-type appraisal would lead to better decisions overall.

In order to maximize its potential value, CBA needs to be sufficiently broad. Excluding impacts on the grounds they are poorly understood becomes problematic when these impacts are essential to the project. The better approach is to account explicitly for uncertainty. This imposes rigour on how tradeoffs between various objectives are handled. It also highlights the need for more research to improve knowledge of the impacts of investments in relation to strategic objectives. CBA is evolving, with a gradual expansion of the scope of the analysis. Coupled with the use of transparent summary tables to present results alongside distributional effects and other indicators critical to political priorities, CBA is well suited to addressing changing strategic policy priorities and emerging demands for project programming.

10 It is not clear if that was the rationale but the practice certainly worked in that direction. 


\section{REFERENCES}

Bickel, P. et al. (2006), HEATCO - Developing harmonised European approaches for transport costing and project assessment, IER, Germany (http://heatco.ier.uni-stuttgart.de/)

Eddington, R. (2006), The Eddington Transport study: transport's role in sustaining the UK's productivity and competitiveness, HM Treasury, London.

Gibbons, S. and H. Overman (2009), Productivity in Transport Evaluation Studies, London School of Economics, April, www.dft.gov.uk/pgr/evaluation/evaluationguidance/evalprodimpacts/.

ITF (2007), The Wider Economic Benefits of Transport, International Transport Forum Round Table 140, OECD Publishing, Paris.

Layard, R. and S. Glaister (2001), Cost-benefit analysis - Second edition, Cambridge University Press.

Mackie, P. (2010), Cost-Benefit Analysis in Transport: A UK Perspective, International Transport Forum Discussion Paper 2010-16,

http://internationaltransportforum.org/itrc/DiscussionPapers/DP201016.pdf

Mohring, H. (1961), Land values and the measurement of highway benefits, Journal of Political Economy, $69,3,236-249$.

Quinet, E. (2010), The Practice of Cost-Benefit Analysis in Transport: The Case of France, International Transport Forum Discussion Paper 2010-17, http://internationaltransportforum.org/jtrc/DiscussionPapers/DP201017.pdf

RailPag (no year), Railway Project Appraisal Guidelines, European Commission - European Investment Bank (http://www.eib.org/projects/publications/railpag-railway-project-appraisal-guidelines.htm).

Ramirez Soberanis, V. (2010), The Practice of Cost Benefit Analysis in the Transport Sector: A Mexican Perspective, International Transport Forum Discussion Paper 2010-18, http://internationaltransportforum.org/itrc/DiscussionPapers/DP201018.pdf

Small, K.A. (1999), Project evaluation, in: J. Gómez-Ibáñez, W.B. Tye and C. Winston (eds.), Essays in transportation economics and policy - a handbook in honour of John R. Meyer, Brookings Institution Press, Washington D.C., 137-180.

Tomlinson, P. (2004), United Kingdom - The evolution of strategic environmental assessment, integrated assessment and decision making in transport planning, in: Assessment and decision making for sustainable transport, ECMT-OECD, Paris, 119-200. 